\title{
Niche Induces Dedifferentiation
}

\section{Puja Sarkar, Aditi Kapoor, Jay Narayan Yadav and Sudhir Kumar*}

School of Biotechnology, IGNOU-I2IT Centre of Excellence for Advanced Education and Research, Pune, Maharashtra, India

\begin{abstract}
Background: Niche plays an important role in deciding the fate of the cell. Three dimensional (3-D) cell culture systems can provide conditions for the cells to revert back to de-differentiated state. Here, egg white is used as a scaffold as well as nutritive medium for the 3-D culture, as it provides nutrients for the cells to grow without extra media. In order to compare the growth of spheroids, another model was also taken into account that is gelatin coated plate. The difference between these two models was that the egg white acted as scaffold and provided additional nutrients for the growth of spheroids, while gelatin provided conditions for low attachment only.
\end{abstract}

Method: Low attachment plates were prepared using egg white and gelatin for the spheroids to grow on it. RNA from cells grown on both $2 \mathrm{D}$ and $3 \mathrm{D}$ culture condition were extracted using trizol method. The concentration of RNA was determined by repeated OD measurements of aliquots at a wavelength of $260 \mathrm{~nm}$ and c-DNA was constructed using Fermentas kit. Finally, gene expressions were checked by PCR using thermo cycler.

Conclusion: The cells had grown into spheroids on egg white based plate rather than gelatin coated plate. Gene expression was found to be upregulated in cells grown on egg white. Thus, it was proved that the niche provided by the egg white has induced de-differentiation, which leads to the acquisition of a stem cell like properties.

\section{Keywords: Niche; Dedifferentiation; 3D culture; Stem cell}

\section{Introduction}

Cellular dedifferentiation has been implicated in cancer [1]. Cancer can only be established from cells that have the potential to divide, but do not differentiate terminally. One theory suggests that tumors may arise from the unrestrained growth of dedifferentiated cells that resemble embryonic stem cells, the term used is cancer stem cells $[2,3]$. The reversal of cellular differentiation or dedifferentiation has fascinated biologists for many decades [4]. Studies suggest that dedifferentiation occurs not only during large-scale cellular regeneration, but also at low levels to replenish stem cells lost due to normal turnover [5]. Transcription factors, such as Oct4, Sox 2 and Nanog regulate the expression of selected genes, and are used to create pluripotent cells [68]. To maintain the cancer stem cell (CSC) pool and support the growth of primary tumors [6], the niche plays an important role in reverting non tumorigenic cells into CSCs [9]. The processes involved in CSC development are related to the epithelial mesenchymal transition that leads to tumor invasion and dissemination [10].

Oct- 4 and Sox- 2 genes have been identified as crucial transcriptional regulators involved in the induction process whose absence makes induction impossible, while Nanog have been identified to increase the induction efficiency [11]. These three transcription factors regulate genes with two distinct and opposing functions: self-renewal and differentiation [12]. When Oct-4, Sox-2 and Nanog are expressed and the switch is on, the self-renewal genes are on and the differentiation genes are off [13]. Nanog binds to the promoter regions of Oct- 4 and Sox-2, as well as to its own. In addition, the Oct-4 Sox-2 heterodimer regulates Nanog, Oct- 4 and Sox- 2 individually. Many of these targeted genes are themselves transcription factors, some are responsible for maintaining ES cells by controlling self -renewal and pluripotency, and others perform key developmental functions that include differentiation into extra-embryonic, endodermal, mesodermal and ectodermal cell types [14]. Hence, the stem cell can be manipulated to be self-renewing without the requirement of input signals.

Cells cultured in 2D systems have been shown to differ remarkably in their morphology, proliferation and differentiation from those growing in $3 \mathrm{D}$ environment $[15,16]$. 3D cell culture matrices, also known as 3D scaffolds, were recently introduced as a way to overcome the limitations of traditional 2D cell culture $[17,18]$. Extensive studies have shown that growing cells within 3D scaffolds diminishes the gap between cell culture and physiological tissues [19]. Therefore, a 3D cell culture system may prove more advantageous over conventional 2D cell culture system [20]. The currently available 3-D cell culture media are cost-prohibitive for regular use by the majority of research laboratories [21].

\section{Materials and Methods}

\section{Preparation of egg white based plate}

The fertilized eggs were procured from Venkateshwara hatcheries, while the un-fertilized eggs were purchased from the market. The outer shell of the egg was cleaned with $70 \%$ ethanol. A small hole in the shell was made using a sterile scalpel under laminar hood and the hole was widen slowly using bend forceps. The egg white was poured carefully into a $50 \mathrm{ml}$ falcon tube, so that the yolk does not get mixed with the egg white. Approximately, $30 \mathrm{ml}$ of egg white can be obtained from each egg and this was aliquoted into $2 \mathrm{ml}$ sterile eppondorf tubes and stored at $-80^{\circ} \mathrm{C}$ for storage. For preparation of egg white coated plate, the egg white aliquotes were thawed and heated for $15 \mathrm{~min}$ at $60^{\circ} \mathrm{C}$ in a heating block, in order to sterilize the egg white. Increased temperature may lead to protein degradation or coagulation, so care must be taken

${ }^{*}$ Corresponding author: Sudhir Kumar, School of Biotechnology, IGNOU-I2IT Centre of Excellence for Advanced Education and Research, P14, Rajiv Gandhi Infotech Park, Phase 1, Hinjewadi, Pune, Maharashtra-411057, India, Tel: +91-2022933441; Fax: +91-2022934592; E-mail: sudhirk@isquareit.ac.in

Received September 25, 2013; Accepted October 23, 2013; Published October 26, 2013

Citation: Sarkar P, Kapoor A, Yadav JN, Kumar S (2013) Niche Induces Dedifferentiation. J Bioanal Biomed 5: 102-107. doi:10.4172/1948-593X.1000089

Copyright: @ 2013 Sarkar P, et al. This is an open-access article distributed under the terms of the Creative Commons Attribution License, which permits unrestricted use, distribution, and reproduction in any medium, provided the original author and source are credited. 
and the tubes must be shaken at regular intervals. The egg white should be added directly to the middle of the wells without touching the side walls, because touching may result in contamination.

\section{Preparation of gelatin coated plates}

Gelatin (from bone) was purchased from Loba Chemie Company (India). Gelatin solution of $1 \%$ concentration was prepared by dissolving 0.5 gram of gelatin in $50 \mathrm{ml}$ of distilled autoclaved water at $37^{\circ} \mathrm{C}$. The blended solution was filtered using $0.2 \mu \mathrm{m}$ filter membrane from Millipore, and then it was used to coat the polystyrene culture plates. The plates were incubated at $37^{\circ} \mathrm{C}$ for at least one day for better coating.

\section{Cell culture}

Confluent flasks of HeLa and HEK-293 cells were trypsinized and cell suspensions were made. Cells were counted using hemocytometer and approximately 50,000 cells were loaded on each well of 6-well plate. Three sets were prepared, one for fertilized egg white, the other for un-fertilized egg white, and the third was for gelatin coated plates. The plates were then placed in the incubator with $5 \% \mathrm{CO}_{2}$ and $37^{\circ} \mathrm{C}$. Everyday the plate were monitored and analyzed the morphology and size of spheroids. The media was exhausted for the cells loaded on gelatin coated plate by day 4 , while the spheroids grew without additional media on egg white coated plates.

\section{Spheroid growth}

For growth analysis, we measured the size of 10 spheroids grown on fertilized egg white, un-fertilized egg white and gelatin coated plates. Images were captured at $10 \mathrm{X}$ from day 0 to day 4 . The diameters of spheroids were measured using Leica software and graph was plotted using sigma plot.

\section{Spheroids isolation}

The total content from a well of 6 -well plate collected in a 15 $\mathrm{ml}$ falcon tube. $3 \mathrm{ml}$ of PBS was added to it and centrifuged using REMI R-8C DX laboratory centrifuge at $525 \mathrm{~g}$ for 5 minutes. After centrifugation, there were two separate layers visible. Slowly the upper clear layer was pipette out without disturbing the lower layer, where the spheroids are present along with egg white fibers. Again, $3 \mathrm{ml}$ of PBS was added to it and centrifuged at $1450 \mathrm{~g}$ for 5 minutes, the spheroids along with egg fiber starts to get settled at the bottom of the tube. This was repeated until the spheroids, along with the egg fibers get settled totally. Discard the PBS from the top without disturbing the spheroids and $1 \mathrm{ml}$ of trypsin was added and incubated at $37^{\circ} \mathrm{C}$ for $2-3$ minutes. DMEM media with $10 \%$ FBS was added to it and flushed properly using a pipette. It was centrifuged at 1500 RPM for 5 minutes, discard the supernatant and dissolve the pellet in $1 \mathrm{ml}$ DMEM with $10 \%$ FBS. Load this cell suspension to a normal cell culture plate and observed every day for differentiation.

\section{PCR}

Total RNA was extracted from the spheroid cultured on fertilized egg white, un-fertilized egg white and gelatin based plates using the trizol reagent. Reverse transcription reactions were performed with random primers from the c-DNA kit (Fermentas). PCR was carried out using master mix (Fermentas) in the thermocycler (Biorad).

The primers were Oct-4: F 5'-TTTTGGTACCCAGGCTATG-3', R 5'-CAAAAACCCTGGCACAAACT-3'; Sox-2: F 5'-ACACCAATCCCATCCACACT-3', R 5'-GCAAACTTCCTGCAAAGCTC-3'; Nanog: F 5'-ATGCCCATCCAGTCAATCTC-3',R 5'-ACACAGTGAAACCCCGTCTC-3'; GAPDH: F 5'-GTCAGTGGTGGACCTGACCT-3', R 5'-TGAGGAGGGGAGATTCAGTG-3'.

\section{Results and Discussion}

\section{Spheroid growth of HeLa and HEK-293 cells}

To test the spheroid growth in both fertilized and unfertilized egg white, HeLa as well as HEK-293 cells were cultured side by side. Around $7 \times 10^{5}$ HeLa and HEK-293 cells were loaded on each of 75 $\mathrm{mm}$ petri plates coated with fertilized and un-fertilized egg white and placed in an incubator with $37^{\circ} \mathrm{C}$ and $5 \% \mathrm{CO}_{2}$. Those cells that were in suspended state in the egg white formed compact structure from day 1 itself, while most of the cells adhered to the bottom of the culture plate (Figure 1 and 2). Both the conditions promoted the growth of the spheroid. It was observed that the spheroids have grown faster in the fertilized egg white as compared to un-fertilized egg white (Figure 3).

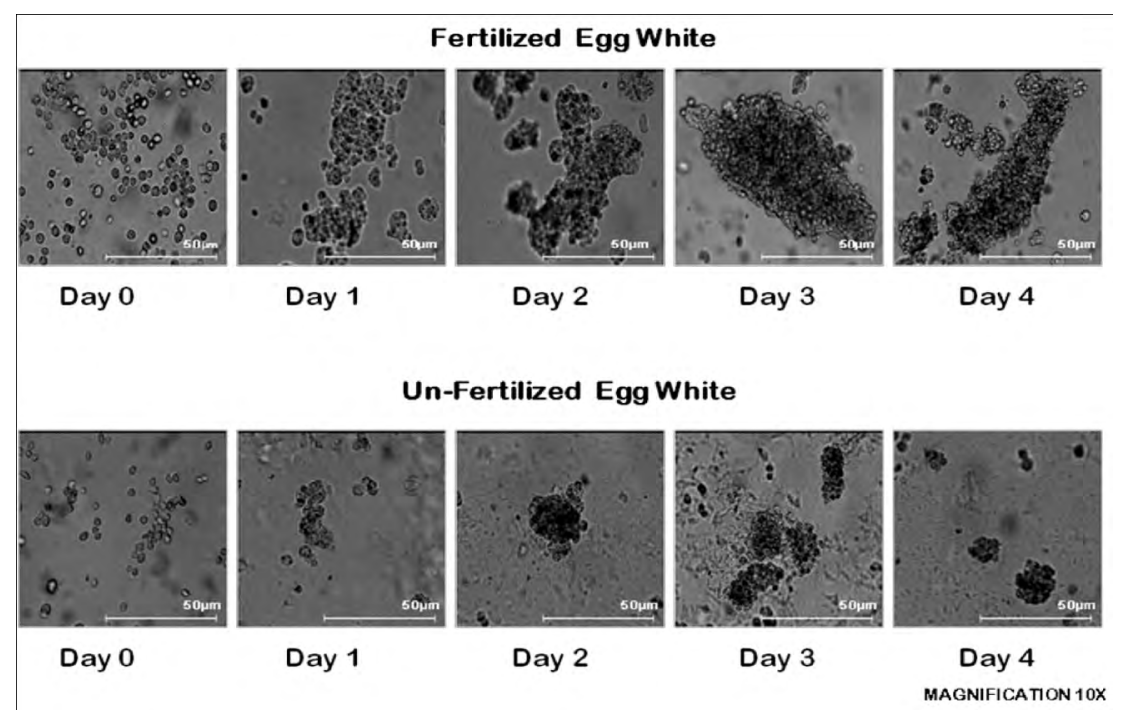

Figure 1: HeLa cells grown in fertilized and un-fertilized egg white (3-D culture) at different time points. 


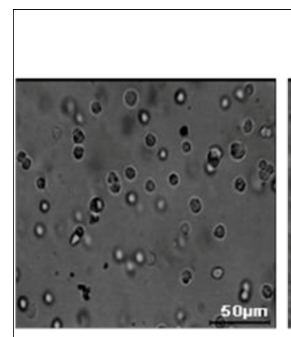

Day 0

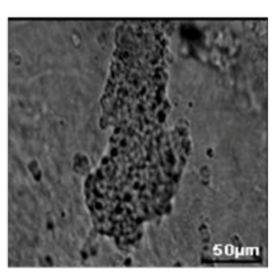

Day 1
Fertilized Egg White

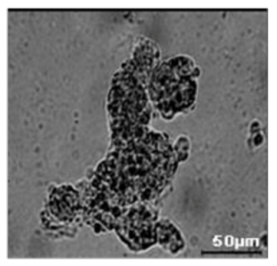

Day 2

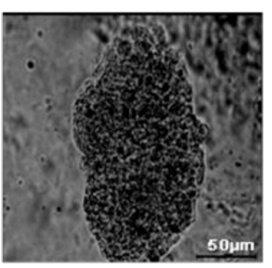

Day 3

\section{Un-Fertilized Egg White}

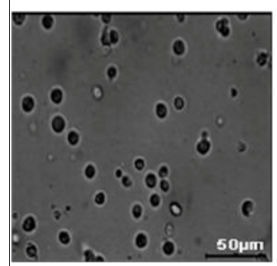

Day 0

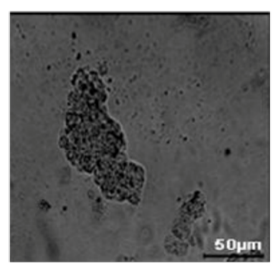

Day 1

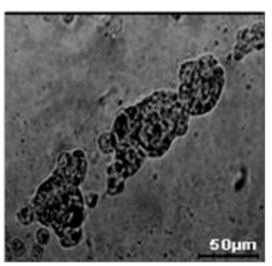

Day 2

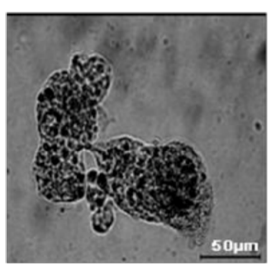

Day 3

MAGNIFICATION $10 X$

Figure 2: HEK-293 cells grown in fertilized and un-fertilized egg white (3-D culture) at different time points.
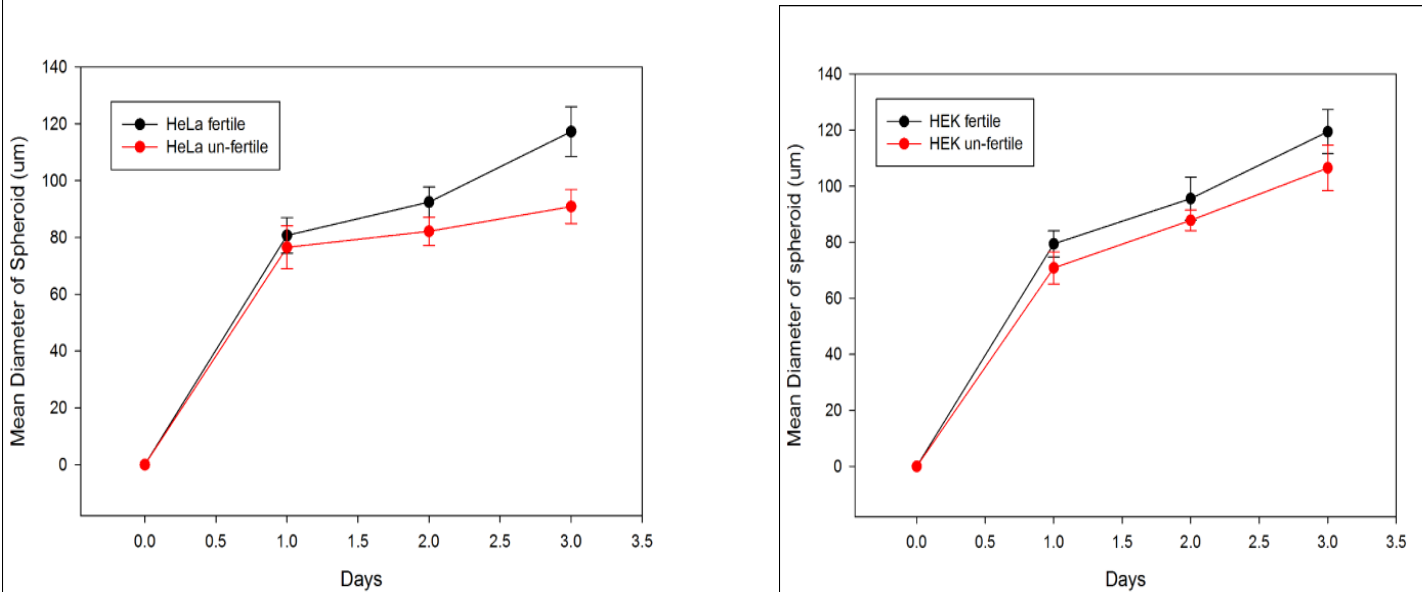

Figure 3: Spheroid size of HeLa and HEK-293 cells on fertilized and un-fertilized egg white at different time points.

\section{Single cell isolation from spheroids grown on egg white}

Single cells were isolated from day 3 , day 5 and day 7 spheroids and the morphological changes were monitored from day 0 to day 4. Initially, the cells were holoclones and as the day increased, there were transition to meroclones and finally to paraclones. As the days of spheroid culture proceeded, the single viable cells isolated from spheroids reduced (Figure 4).

\section{Spheroid differentiation and de-differentiation}

Spheroids were isolated at day 3 and it was loaded on gelatin coated plate. The plate was monitored till day 9. The spheroids were cultured in media with FBS. The media was changed at day 5 , as it was exhausted. Till day 5, the differentiation of spheroids was seen, and from day 6, there was de-differentiation observed till day 7. Later on, differentiation was seen at day 8 onwards. This shows the cells under stress reverted back and induced de-differentiation (Figure 5).

\section{Gene expression}

c-DNA was prepared using Fermentas kit from the RNA and expression of the stem cell genes were checked using PCR. Expression of Oct-4, Sox-2, Nanog and GAPDH were checked in HeLa and HEK 293 cells cultured on both 2D and 3D (fertilized and unfertilized egg white). GAPDH is a house keeping gene that is expressed equally in all the three types of conditions in HeLa and HEK 293 cells. Oct-4, Sox-2 and Nanog were expressed in all the three conditions, but the expression level of Sox-2 and Nanog is less in unfertilized condition in HeLa cells. The expression of Oct- 4 is less in $2 \mathrm{D}$ condition, while Sox- 2 is expressed in $3 \mathrm{D}$ fertilized egg white and Nanog is not expressed in any condition in HEK 293 cells, which shows that nanog is involved with self renewal of undifferentiated cells (Figure 6 and 7). 
Citation: Sarkar P, Kapoor A, Yadav JN, Kumar S (2013) Niche Induces Dedifferentiation. J Bioanal Biomed 5: 102-107. doi:10.4172/1948593X.1000089

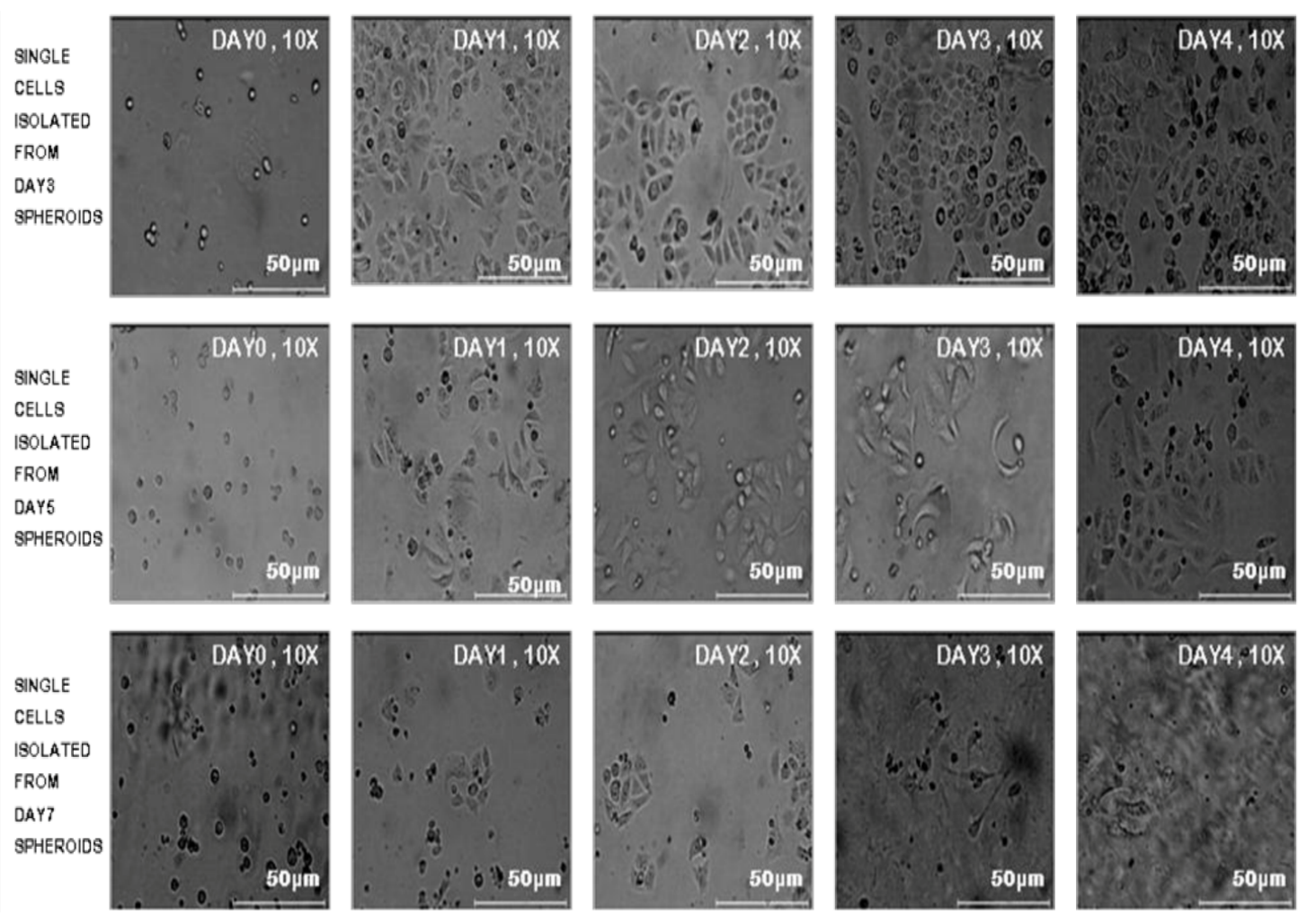

Figure 4: Single cell isolation from spheroids cultured at different time points.
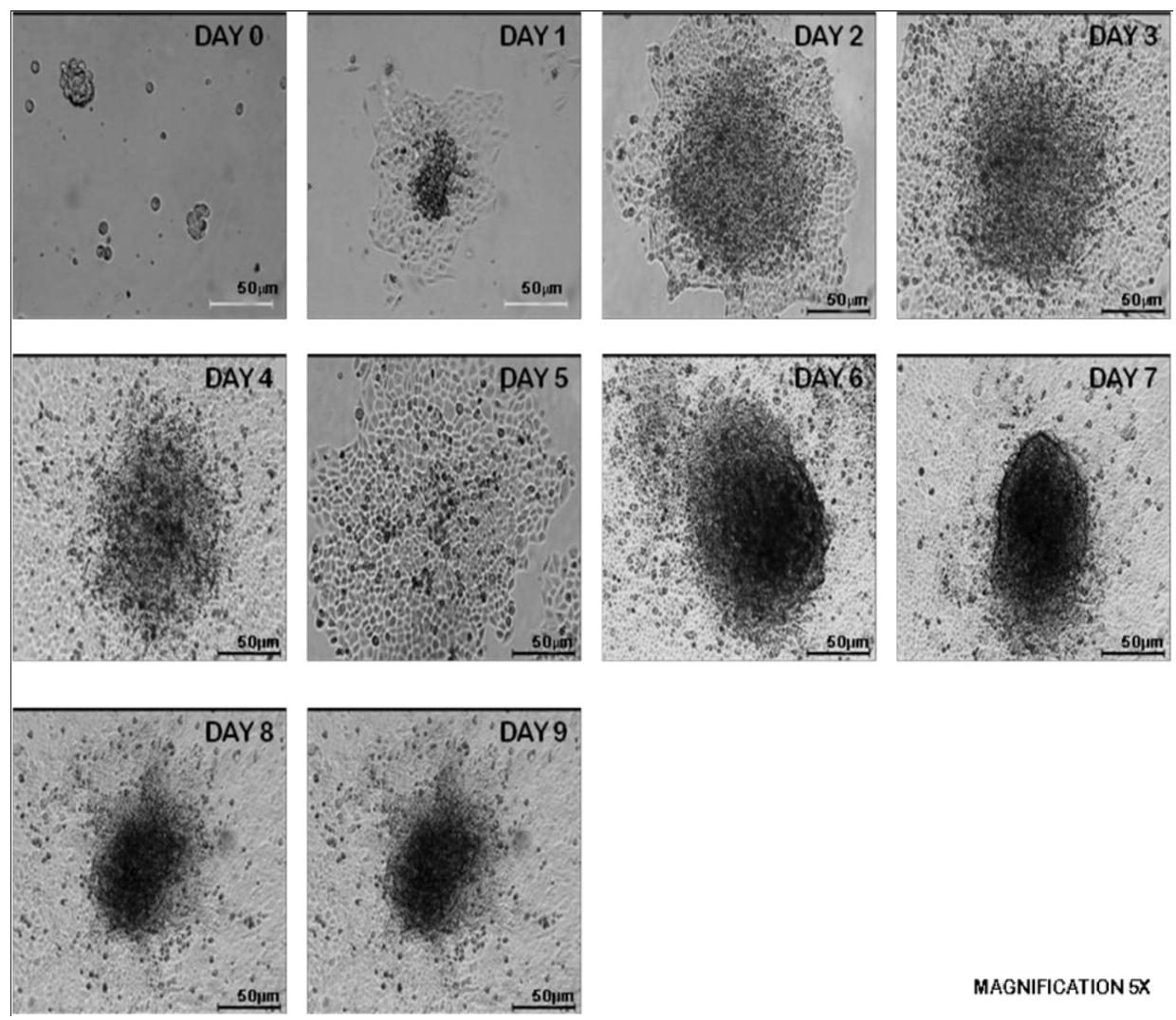

Figure 5: Differentiation and de-differentiation of day 3 spheroids of HeLa cells up to 9 days. 
Citation: Sarkar P, Kapoor A, Yadav JN, Kumar S (2013) Niche Induces Dedifferentiation. J Bioanal Biomed 5: 102-107. doi:10.4172/1948593X.1000089

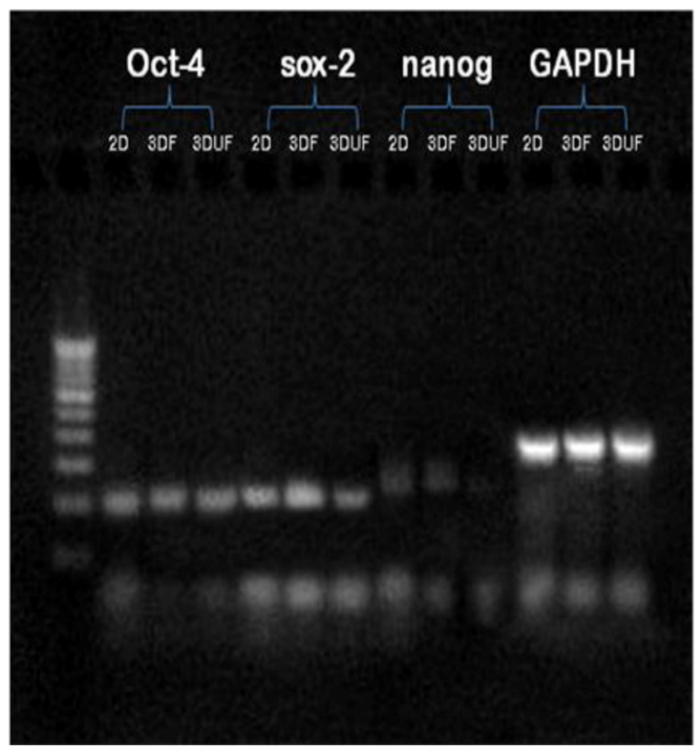

\section{Gene Expression Profile in Hela}

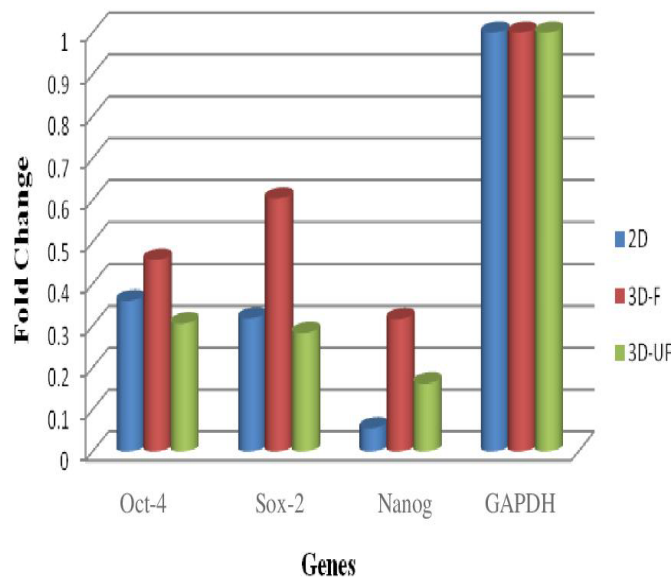

Figure 6: Stem cell gene expressions of HeLa cells grown in 2D (2-Dimentional), 3DF (3-Dimentional Fertilized egg white) and 3DUF (3-Dimentional Un-Fertilized egg white) coated plates.
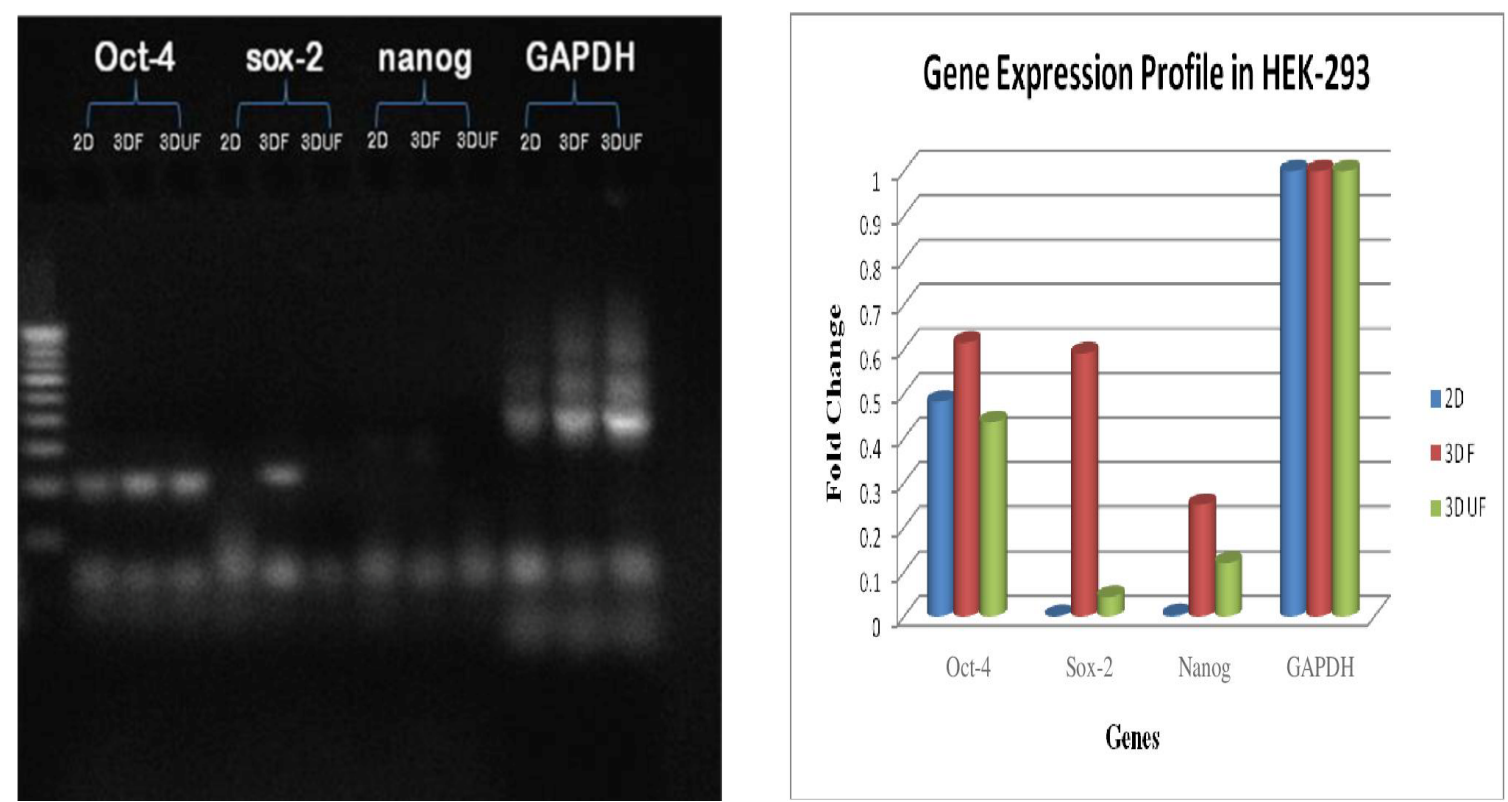

Figure 7: Stem cell gene expression of HEK-293 cells grown in 2D (2-Dimentional), 3DF (3-Dimentional Fertilized egg white) and 3DUF (3-Dimentional Un-Fertilized egg white) coated plates.

No stem cell genes were expressed for the HeLa cells grown on gelatin coated plates. GAPDH expression shows that the cells were healthy, but it did not have the stemness. So it appears that gelatin is not suitable niche for de-differentiation. Since HEK-293 is a transformed embryonic kidney cells, therefore Oct- 4 and Sox- 2 were expressed even on gelatin coated plates. GAPDH expression is same for all the three concentrations.

Niche plays an important role in deciding cell fate [22,23]. This can be explained as the fertilized egg white provides nourishment and protection to the developing embryo [21]. The cells utilize these available nutrients and hence grow better and maintain the stemness. The extra nutrients present in fertilized egg white may be absent or present in very minute quantities in the un-fertilized egg white, therefore spheroid formation is less [24,25].

Oct-4, Sox-2 and Nanog are the core transcription factor for supporting stemness. The study demonstrated that the spheroid forming cells which are cultured in egg white coated plate possess CSC properties when compared with the cells grown on $2 \mathrm{D}$ culture condition. 
Citation: Sarkar P, Kapoor A, Yadav JN, Kumar S (2013) Niche Induces Dedifferentiation. J Bioanal Biomed 5: 102-107. doi:10.4172/1948593X.1000089

\section{Conclusion}

The spheroids grown on fertilized egg white showed better result than that of spheroids grown on un-fertilized egg white coated plates. The gene expression also proves that the spheroids on fertilized egg white had more stemness when compared to un-fertilized egg white and cells cultured as monolayers ( $2 \mathrm{D}$ cells). 3D cell culture is better than $2 \mathrm{D}$ cell culture as it mimics the tumor micro-environment, as well as embryo's growth.

In general, the growth of cells on conventional 2D plastic substrate has not changed significantly for many years. New innovative ways of culturing cells are becoming available that will improve current practice, cell growth and performance. The evidence demonstrating the advantages of $3 \mathrm{D}$ cell growth is compelling, as is the need for technology that enables routine $3 \mathrm{D}$ cell culture.

\section{Acknowledgement}

We thank SoBT, IGNOU- I2IT Centre of Excellence for Advanced Education and Research, Pune, for their support. The authors declare no conflict of interest.

\section{References}

1. Daley GQ (2008) Common themes of dedifferentiation in somatic cell reprogramming and cancer. Cold Spring Harb Symp Quant Biol 73: 171-174.

2. Caussinus E, Hirth F (2007) Asymmetric stem cell division in development and cancer. Prog Mol Subcell Biol 45: 205-225.

3. Liu Z, Li Q, Li K, Chen L, Li W, et al. (2013) Telomerase reverse transcriptase promotes epithelial-mesenchymal transition and stem cell-like traits in cancer cells. Oncogene 32: 4203-4213.

4. Becker RO (2002) Induced dedifferentiation: A possible alternative to embryonic stem cell transplants. Neuro Rehabilitation 17: 23-31.

5. Sheng XR, Matunis EL (2009) Make room for dedifferentiation. Fly (Austin) 3: 283-285.

6. Pal R, Mamidi MK, Das AK, Bhonde R (2013) Comparative analysis of cardiomyocyte differentiation from human embryonic stem cells under $3-D$ and 2-D culture conditions. J Biosci Bioeng 115: 200-206.

7. Ramalingam S, London V, Kandavelou K, Cebotaru L, Guggino W, et al. (2013) Generation and genetic engineering of human induced pluripotent stem cells using designed zinc finger nucleases. Stem Cells Dev 22: 595-610.

8. Storm MP, Orchard CB, Bone HK, Chaudhuri JB, Welham MJ (2010) Threedimensional culture systems for the expansion of pluripotent embryonic stem cells. Biotechnol Bioeng 107: 683-695.

9. Leon J, Ferrandiz N, Acosta JC, Delgado MD (2009) Inhibition of cell differentiation: A critical mechanism for MYC-mediated carcinogenesis? Cell Cycle 8: 1148-1157.
10. Liu HG, Zhang XH (2009) How to search for specific markers of cancer stem cells. Asian Pac J Cancer Prev 10: 177-180.

11. Chambers I, Colby D, Robertson M, Nichols J, Lee S, et al. (2003) Functiona expression cloning of Nanog, a pluripotency sustaining factor in embryonic stem cells. Cell 113: 643-655.

12. Boyer LA, Lee TI, Cole MF, Johnstone SE, Levine SS, et al. (2005) Core transcriptional regulatory circuitry in human embryonic stem cells. Cell 122 : 947-956.

13. Chickarmane V, Troein C, Nuber UA, Sauro HM, Peterson C (2006) Transcriptional dynamics of the embryonic stem cell switch. PLoS Comput Biol 2: e123.

14. Loh YH, Wu Q, Chew JL, Vega VB, Zhang W, et al. (2006) The Oct4 and Nanog transcription network regulates pluripotency in mouse embryonic stem cells. Nat Genet 38: 431-440.

15. Baker BM, Chen CS (2012) Deconstructing the third dimension: how 3D culture microenvironments alter cellular cues. J Cell Sci 125: 3015-3024.

16. Greiner AM, Richter B, Bastmeyer M (2012) Micro-engineered 3D scaffolds for cell culture studies. Macromol Biosci 12: 1301-1314.

17. Maltman DJ, Przyborski SA (2010) Developments in three-dimensional cell culture technology aimed at improving the accuracy of in vitro analyses. Biochem Soc Trans 38: 1072-1075.

18. Zschenker O, Streichert T, Hehlgans S, Cordes N (2012) Genome-wide gene expression analysis in cancer cells reveals 3D growth to affect ECM and processes associated with cell adhesion but not DNA repair. PLoS One 7: e34279.

19. Urciuolo F, Imparato G, Guaccio A, Mele B, Netti PA (2012) Novel strategies to engineering biological tissue in vitro. Methods Mol Biol 811: 223-244.

20. Yamada KM, Cukierman E (2007) Modeling tissue morphogenesis and cancer in 3D. Cell 130: 601-610.

21. Kaipparettu BA, Kuiatse I, Tak-Yee Chan B, Benny Kaipparettu M, Lee AV, et al. (2008) Novel egg white-based 3-D cell culture system. Biotechniques 45 : $165-168$.

22. Caron MM, Emans PJ, Coolsen MM, Voss L, Surtel DA, et al. (2012) Redifferentiation of dedifferentiated human articular chondrocytes: comparison of 2D and 3D cultures. Osteoarthritis Cartilage 20: 1170-1178.

23. Lund AW, Yener B, Stegemann JP, Plopper GE (2009) The natural and engineered $3 D$ microenvironment as a regulatory cue during stem cell fate determination. Tissue Eng Part B Rev 15: 371-380.

24. Sokol JP, Schiemann WP (2004) Cystatin C antagonizes transforming growth factor beta signaling in normal and cancer cells. Mol Cancer Res 2: 183-195.

25. Guérin-Dubiard C, Pasco M, Mollé D, Désert C, Croguennec T, et al. (2006) Proteomic analysis of hen egg white. J Agric Food Chem 54: 3901-3910. 